\title{
Proteomic analysis of oridonin-induced apoptosis in multiple myeloma cells
}

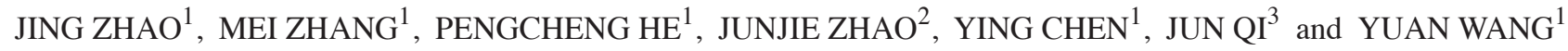 \\ ${ }^{1}$ Department of Hematology, The First Affiliated Hospital, School of Medicine, Xi'an Jiaotong University; \\ ${ }^{2}$ Department of Genetics and Molecular Biology, School of Medicine, Xi'an Jiaotong University; \\ ${ }^{3}$ Institute of Xi'an Blood Bank, Shaanxi Blood Center, Xi'an, Shaanxi 710061, P.R. China
}

Received January 3, 2016; Accepted December 13, 2016

DOI: $10.3892 / \mathrm{mmr} .2017 .6213$

\begin{abstract}
Oridonin is a diterpenoid compound isolated from the medicinal herb Rabdosia rubescens, and has shown marked antitumor effects against different types of cancer. However, the definitive systematic molecular mechanism underlying the antitumor activity of oridonin in multiple myeloma remains to be elucidated. In the present study, cell viability and cytotoxicity were examined to determine the appropriate concentration for proteomic investigation. In addition, cell apoptosis was evaluated using flow cytometry and transmission electron microscopy. A proteomic investigation using a two-dimensional electrophoresis system and mass spectrometry was performed to identify and characterize the global proteome of the apoptosis induced by oridonin. Of the proteins identified, seven were involved in the anticancer effects of oridonin. Regulation of the expression and function of target proteins, stathmin, dihydrofolate reductase and pyruvate dehydrogenase E1 $\beta$, may be potential, therapeutic strategies to effectively treat multiple myeloma. These findings provide novel information on the molecular mechanisms underlying the anticancer properties of oridonin in multiple myeloma.
\end{abstract}

\section{Introduction}

Multiple myeloma is defined as a plasma cell malignancy characterized by the hyperplasia of plasma cells in the bone marrow; this malignancy is usually associated with high levels of monoclonal immunoglobulin in the blood, and leads to pathological fracture, ostealgia, infection, hypercalcemia and anemia (1). For over half a century, multiple myeloma therapy has shown only limited success, with approximately one third of patients not responding to chemotherapy and the

Correspondence to: Dr Mei Zhang, Department of Hematology, The First Affiliated Hospital, School of Medicine, Xi'an Jiaotong University, 277 Yanta West Road, Xi'an, Shaanxi 710061, P.R. China E-mail: zhangmei@medmail.com.cn

Key words: oridonin, LP-1 cell, multiple myeloma, apoptosis, proteomics remainder eventually relapsing if they do not succumb to other diseases (2).

Oridonin is a diterpenoid compound isolated from the Chinese medicinal herb, Rabdosia rubescens and exhibits marked antitumor activity. Accumulating evidence has suggested that oridonin is able to inhibit the progression of tumors, thereby alleviating the tumor burden and cancer syndrome (3-6). Oridonin has been reported to induce apoptosis and autophagy through the Fas/FasL-mediated signaling cascade (7). Additionally, oridonin has been shown to be involved in the suppression of cell cycle progression and/or the induction of cancer cell death in various in vitro trials (8-10). Although oridonin is closely associated with the induction of apoptosis, the definitive systematic molecular mechanism underlying the action of oridonin in multiple myeloma therapy remains to be elucidated and awaits further investigation.

Currently, a proteomic approach is used in the molecular analysis of various types of human cancer (11). However, there has been no systematic identification of the global proteome of oridonin-induced apoptosis in multiple myeloma LP-1 cell lines until now. To further understand the molecular mechanism of oridonin in multiple myeloma therapy, the present study performed proteomic analysis using a two-dimensional gel electrophoresis (2-DE)-based system and mass spectrometry (MS).

\section{Materials and methods}

Cell culture. The LP-1 multiple myeloma cell line was obtained from the China Center for Type Culture Collection (Wuhan, China) and was stored in Shanghai Institute of Hematology, Ruijin Hospital (Shanghai, China). The 8226 human multiple myeloma cell line was purchased from American Type Culture Collection (Manassas, VA, USA). The cells were cultured in RPMI-1640 (Invitrogen; Thermo Fisher Scientific, Inc., Waltham, MA USA) and supplemented with $10 \%$ heat-inactivated fetal bovine serum (FBS; Hyclone; GE Healthcare Life Sciences, Logan, UT, USA) at $37^{\circ} \mathrm{C}$ in an atmosphere containing $5 \% \mathrm{CO}_{2}$. The cells were maintained at an optimal cell density between $5 \times 10^{5}$ and $1 \times 10^{6} / \mathrm{ml}$. Oridonin was purchased from Xi'an Traditional Chinese Drug Company (Xi'an, China), the purity of which was determined to be $97 \%$ using high-performance liquid chromatography. A 
stock solution of oridonin was prepared in dimethyl sulfoxide (DMSO; Sigma-Aldrich; Merck KGaA, Darmstadt, Germany) and the aliquots were stored at $-20^{\circ} \mathrm{C}$.

Cell viability assay. Cytotoxicity was assessed using a 3-(4,5-dimethylthiazol-2-yl)-2,5-diphenyl tetrazolium bromide (MTT) assay. The control and oridonin-treated LP-1 cells $(0,5,10,15,20,25$ and $50 \mu \mathrm{M})$ in the logarithmic growth phase were cultured in a sterile 96 -well plate at an optimal cell density of $0.5-1 \times 10^{5} / \mathrm{ml}$ per well, and were incubated at $37^{\circ} \mathrm{C}$ in a $5 \% \mathrm{CO}_{2}$ incubator for $12,24,48$ and $72 \mathrm{~h}$. Subsequently, $20 \mu 1$ of MTT working solution was added to each of the cultured wells, and the cells were incubated for $4 \mathrm{~h}$ at $37^{\circ} \mathrm{C}$. The culture medium supernatant was removed from the wells after each plate was centrifuged $(800 \times \mathrm{x}$ for $15 \mathrm{~min})$ and replaced with $200 \mu \mathrm{l}$ DMSO at room temperature. Following solubilization, the absorbance of each well was measured using a computer-controlled microplate analyzer at $490 \mathrm{~nm}$. Each treatment was performed in triplicate and each experiment was repeated three times.

Detection of apoptosis using Annexin V FITC/propidium iodide (PI) binding analysis. Flow cytometric analysis using Annexin V FITC (Sigma-Aldrich; Merck KGaA) and PI (Sigma-Aldrich; Merck KGaA) was performed to measure the ratio of apoptotic LP-1 cells. Oridonin was added at a final concentration of $25 \mu \mathrm{M}$ for the experimental group, and the same volume of DMSO was added for the control group. Overall, $10^{6}$ cultured cells were incubated for $24 \mathrm{~h}$ prior to being harvested; the cells were washed twice with cold PBS and resuspended in $500 \mu \mathrm{l}$ Annexin $\mathrm{V}$ binding buffer. The cell suspension was then transferred to a centrifuge tube and incubated with $5 \mu \mathrm{l}$ of Annexin V-FITC at room temperature in the dark for $15 \mathrm{~min}$. The analysis was performed using FACSort flow cytometer (BD Biosciences, Franklin Lakes, NJ, USA) and evaluated using the CellQuest software system version 7.5.3 (BD Biosciences).

Observation using transmission electron microscopy. The apoptotic morphology was monitored using transmission electron microscopy. In the experimental group, the culture medium was replaced with $25 \mu \mathrm{M}$ of oridonin solution. After 24 h, LP-1 cells were collected and fixed with $2.5 \%$ glutaraldehyde for $2 \mathrm{~h}$ at $4^{\circ} \mathrm{C}$. Subsequently; the cells were rinsed three times with PBS and fixed with $1 \%$ osmic acid for $2 \mathrm{~h}$ at $4^{\circ} \mathrm{C}$. The cells were subsequently dehydrated with 30,50 and $70 \%$ ethanol for $10 \mathrm{~min}$ in sequence. Finally, the cells were dipped in Epoxy resin (Epon812) for at least $2 \mathrm{~h}$, freeze-dried for $3 \mathrm{~h}$ and then loaded onto the transmission electron microscope (JEM-100sx; JEOL, Ltd., Tokyo, Japan) for observation.

Proteomic sample preparation and 2-DE. The frozen cell samples were dissolved in lysis buffer $\left(100 \mu \mathrm{l}\right.$ per $10^{7}$ cells), containing $40 \mathrm{mM}$ Tris base, $8 \mathrm{M}$ urea, $2 \mathrm{M}$ thiourea, $4 \%$ CHAPS, $1 \%$ dithiothreitol (DTT), $1 \mathrm{mM}$ EDTA and a $1 \mathrm{X}$ protease inhibitor cocktail (Roche Diagnostics GmbH, Mannheim, Germany). The oridonin treated group and control group cell precipitates were resuspended, oscillated by vortexing for $2 \mathrm{~min}$ and then freeze-thawed three times in liquid nitrogen; solubilization was achieved using ultrasound in ice water. Following centrifugation at $25,000 \mathrm{x} g$ or $30 \mathrm{~min}$ at $4^{\circ} \mathrm{C}$, the supernatant was used as the 2-DE sample, and the protein concentration was determined using the Bradford method (12) and a Bradford assay kit (Bio-Rad Laboratories, Inc., Hercules, CA, USA). The protein samples were stored in aliquots and were frozen at $-80^{\circ} \mathrm{C}$ until further use.

The 2-DE was performed as described by Görg et al (13). The first-dimension separation was performed using commercial immobilized $\mathrm{pH}$ gradient dry strips $(18 \mathrm{~cm}$; $\mathrm{pH} 3-10$; nonlinear; GE Healthcare Life Sciences, Chalfont, UK). The samples were diluted in rehydration solution containing $8 \mathrm{M}$ urea, $2 \%$ CHAPS, $0.5 \%$ immobilized pH gradient (IPG) buffer (GE Healthcare Life Sciences) and $20 \mathrm{mM}$ DTT. The strips were rehydrated at $20^{\circ} \mathrm{C}$. The proteins were then focused using the IPGphor system (GE Healthcare Life Sciences) according to the manufacturer's protocol (14). The IPG strips were rehydrated at $30 \mathrm{~V}$ for $12 \mathrm{~h}$ and focused at $500 \mathrm{~V}$ for $30 \mathrm{~min}$, $2,000 \mathrm{~V}$ for $30 \mathrm{~min}$ and $5,000 \mathrm{~V}$ for $30 \mathrm{~min}$, following which the voltage was gradually increased to $8,000 \mathrm{~V}$ and maintained at $8,000 \mathrm{~V}$ for $160,000 \mathrm{Vh}$. The strips were then equilibrated twice for $15 \mathrm{~min}$ in equilibration buffer, containing $6 \mathrm{M}$ urea, 30\% glycerol and 2\% SDS in $50 \mathrm{mM}$ Tris-HCl buffer (pH 8.8), which was supplemented with $65 \mathrm{mM}$ DTT for the first treatment and $259 \mathrm{mM}$ iodoacetamide for the second treatment. 2-DE was performed using the Protean II Cell system (Bio-Rad Laboratories, Inc.) with a 13\% SDS-polyacrylamide gel at a constant current of $20 \mathrm{~mA} / \mathrm{gel}$ for the initial $40 \mathrm{~min}$, followed by a current of $30 \mathrm{~mA} / \mathrm{gel}$ until the bromophenol blue dye marker reached the bottom of the gel.

Protein spot visualization and analysis of the 2-DE images. Following electrophoresis, the protein spots were visualized using silver nitrate staining, according to the protocol described by Pasquali et al (15), and Coomassie Brilliant Blue R-250 (0.05\% Brilliant Blue) for the analytical and micropreparative gels, respectively. The gels were scanned with an ImageScanner (GE Healthcare Life Sciences) and the 2-DE images were analyzed using ImageMaster ${ }^{\mathrm{TM}} 4.01$ software (GE Healthcare Life Sciences). Only the spots found to be significantly (Student's $t$-test; $\mathrm{P}<0.05$ ) upregulated or downregulated ( $>2$-fold) were selected for in-gel digestion and MS) analysis as the lower variations were not reproducible.

In-gel digestion and Matrix-assisted laser desorption/ionization time of flight mass spectrometry (MALDI-TOF-MS/MS) analysis. For 2-DE, $1.2 \mathrm{mg}$ of the protein sample was dyed with Coomassie brilliant blue. The corresponding differential protein spots were identified, cut, decolorized and in-gel digested, and the peptides were extracted according to the Thermo Finnigan operation process (16). A $1 \mu 1$ volume of sample solution and an equal volume of the saturated matrix solution were mixed and applied to the target plate. All mass spectra of MALDI-TOF-MS were obtained on a Bruker Reflex MALDI-TOF-MS (Bruker-Franzen, Bremen, Germany) in positive ion mode at an accelerating voltage of $20 \mathrm{kV}$. Monoisotopic peptide masses were used to for database searching, allowing for a peptide mass accuracy of $0.3 \mathrm{Da}$ and one partial cleavage. The oxidation of methionine and carbamidomethyl modification of cysteine was considered. The protein identification was performed automatically by 
searching the NCBInr database using the MASCOT search engine (www.matrixscience.co.uk).

Western blot analysis. The oridonin-treated LP-1 and 8226 cells were collected and the proteins were extracted using RIPA lysis buffer containing a protease inhibitor cocktail (Roche Diagnostics $\mathrm{GmbH}$ ). The protein concentrations were determined using a Bio-Rad protein assay (Bio-Rad Laboratories, Inc.). Protein samples $(50 \mu \mathrm{g})$ were separated by $12 \%$ SDS-PAGE and then transferred to polyvinylidene fluoride membranes (Merck KGaA, Darmstadt, Germany) at a constant voltage of $25 \mathrm{~V}$ for $50 \mathrm{~min}$. Following this, membranes were blocked with $5 \%$ fat-free milk solution at room temperature for $2 \mathrm{~h}$, incubated with primary antibodies overnight at $4^{\circ} \mathrm{C}$ and subsequently washed 3 times with TBST. The following primary antibodies were used: monoclonal rabbit anti-Stathmin (catalog no. ab52630; 1:500; Abcam, Cambridge, MA, USA), monoclonal mouse anti-dihydrofolate reductase (catalog no. sc74594; DHFR; 1:1,000; Santa Cruz Biotechnology, Inc., Dallas, TX, USA) and monoclonal rabbit anti-thioredoxin reductase (catalog no. sc365658; TrxR; 1:1,000; Santa Cruz Biotechnology, Inc.). Monoclonal mouse anti- $\beta$-actin was used as a loading control (catalog no. ab6276; 1:1,000; Abcam). Following incubation with horseradish peroxidase-conjugated goat anti-rabbit IgG or goat anti-mouse IgG secondary antibodies occured (catalog no. 31460WB, 31430WB; 1:5,000; Pioneer Biotechnology, Xi'an, China) for $2 \mathrm{~h}$ at room temperature. ECL detection reagents (GE Healthcare Life Sciences) were used to detect signals. The intensity of the stained bands was quantified using a densitometer and normalized to the intensity of the $\beta$-actin bands, which was used as an internal control.

Reverse transcription-quantitative polymerase chain reaction (RT-qPCR) analysis. Total RNA was isolated from cells using TRIzol reagent (Invitrogen; Thermo Fisher Scientific, Inc.) according to the manufacturer's protocol. A total of $1 \mu \mathrm{g}$ RNA and $1 \mu \mathrm{l}$ oligo $(\mathrm{dT})_{18}$ primer was used for reverse transcription using a Reverse Transcription kit (Fermentas; Thermo Fisher Scientific, Inc.). The PCR primers were designed as follows: Stathmin, sense 5'-AAGGCAAGATTGAAGACA CAGGAG-3' and antisense 5'-TGAGGACACCCAAGCAA GACC-3'; DHFR, sense 5'-GGATGCCTTTGTGGAACT GT-3' and antisense 5'-CGTTTCATGGGACATCACTG-3'; and TrxR, sense 5'-GCCCTGCAAGACTCTCGAAATTA-3' and antisense 5'-GCCCATAAGCATTCTCATAGACGA-3'. To normalize the quantities of RNA in the samples, PCR analysis was also performed using primers of GAPDH (sense 5'-GAAGGTGAAGGTCGGAGTC-3' and antisense 5'-GAA GATGGTGATGGGATTTC-3'). The PCR analysis was performed in a total volume of $50 \mu \mathrm{l}$, containing $1 \mu \mathrm{l} \mathrm{cDNA}$, $1 \mu \mathrm{l}$ forward primers, $1 \mu \mathrm{l}$ reverse primers, $22 \mu \mathrm{ldd} \mathrm{H}_{2} \mathrm{O}, 25 \mu \mathrm{l}$ 2X Taq PCR Master mix (Takara Bio, Inc., Otsu, Japan) in an ABI PRISM7000 real-time PCR system (Applied Biosystems; Thermo Fisher Scientific, Inc.). All samples were run in triplicate. The RNA expression levels were calculated using the $2^{\Delta \Delta \mathrm{Cq}}$ method (17).

Statistical analysis. The results are expressed as the mean \pm standard deviation of triplicate samples. Statistical

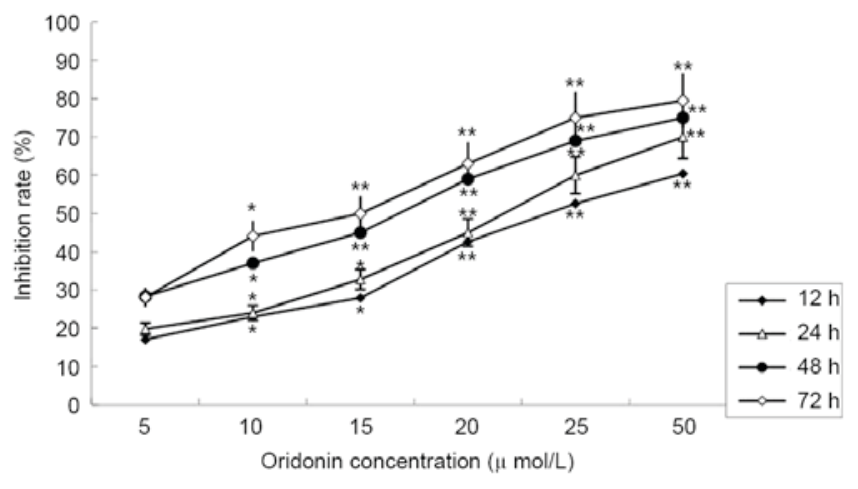

Figure 1. Dose- and time-dependent curve of the inhibition rate of oridonin on the LP-1 cells using an MTT assay. The cells were treated with various concentrations of oridonin or dimethyl sulfoxide (control) for $24 \mathrm{~h}$. Cell viability was measured using an MTT assay. The data are presented as the mean \pm standard deviation of three independent experiments. ${ }^{*} \mathrm{P}<0.05$ and ${ }^{* *} \mathrm{P}<0.01$, vs. control. MTT, 3-(4,5-dimethylthiazol-2-yl)-2,5-diphenyl tetrazolium bromide.

analyses were performed using Student's $t$-test or one-way analysis of variance. $\mathrm{P}<0.05$ was considered to indicate a statistically significant difference.

\section{Results}

MTT assay. The MTT assay revealed that treatment with oridonin caused a significant decrease in cell viability. The LP-1 cells were treated with different concentrations of oridonin $(0-50 \mu \mathrm{M})$, and the inhibition rates ranged between $19.81 \pm 2.89 \%$ at $24 \mathrm{~h}$ and $79.52 \pm 2.37 \%$ at $72 \mathrm{~h}$. The inhibition effect was dose- and time-dependent. The half maximal inhibitory concentration $\left(\mathrm{IC}_{50}\right)$ value was determined to be $25.01 \mu \mathrm{mol} / \mathrm{l}$ at $24 \mathrm{~h}$; this time point was selected for subsequent assays (Fig. 1).

Detection of apoptosis. To determine whether the decrease in MTT activity following exposure to oridonin was attributable to the induction of cellular apoptosis, flow cytometric analysis and evaluation of the ultrastructural characteristics of the cells were performed. Following treatment of the LP-1 cells with oridonin $(25 \mu \mathrm{M})$ for $24 \mathrm{~h}$, the flow cytometry data (Fig. 2A and $B$ ) revealed that the apoptotic rate of the cells was $29.03 \pm 1.27 \%$, compared with the rate of $8.11 \pm 0.73 \%$ in the control cells $(\mathrm{P}<0.05$; Fig. $2 \mathrm{C})$.

To confirm the occurrence of apoptosis, the cells were observed using transmission electron microscopy. The transmission images of the untreated control cells showed intact nuclei and membranes (Fig. 3A-B). By contrast, the LP-1 cells treated with oridonin for $24 \mathrm{~h}$ exhibited chromatin and cytoplasmic condensation, vacuolization, prominent nuclear fragmentation and marginalization (Fig. 3C-F), in addition to mitochondrial swelling.

2-DE and MS analysis. The proteome expression of the cells prior to and following oridonin treatment were monitored using 2-DE-based proteomics. Representative gel images are shown in Fig. 4A. Proteins in the range of 14.4-97 kDa and with isoelectric points of 3-10 were well separated. In total, $>1,000$ spots were detected on the silver staining gel using 
A

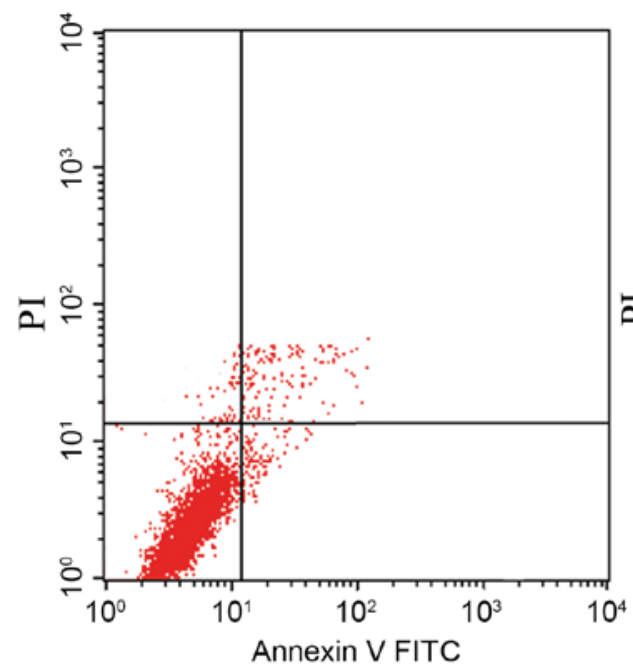

C

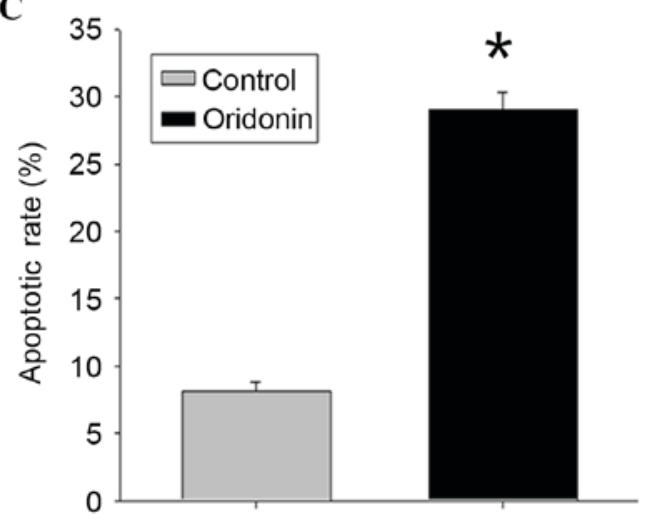

B

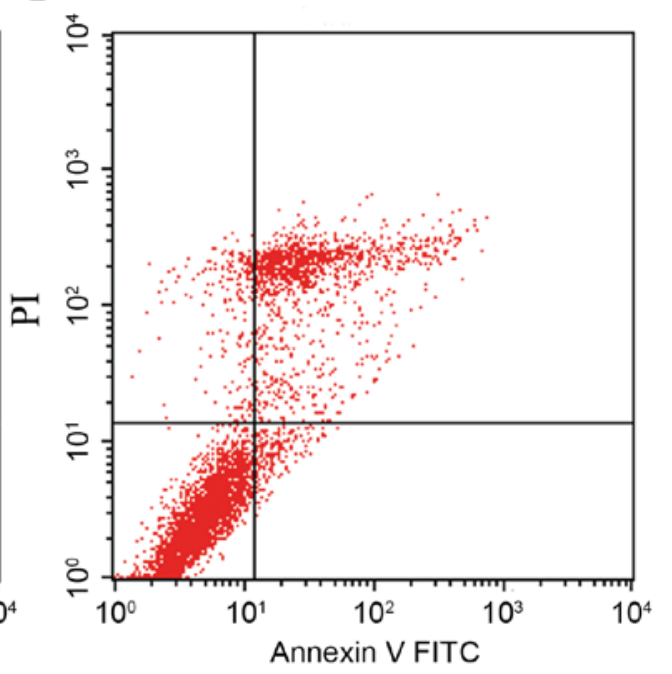

Annexin V FITC

Figure 2. Flow cytometric analysis of apoptosis in LP-1 cells treated with oridonin. Apoptosis was assessed using flow cytometry with Annexin V-FITC/ propidium iodide staining. (A) Untreated control cells. (B) Cells treated with $25 \mu \mathrm{M}$ oridonin for $24 \mathrm{~h}$. (C) Cells with typical apoptotic changes were counted in randomly selected fields containing 500 cells. The percentage of apoptotic cells was calculated and presented as the mean \pm standard deviation of three independent experiments. " $\mathrm{P}<0.05$, vs. control.

ImageMaster ${ }^{\mathrm{TM}}$ 2D Platinum software and manual clear-up. By combining the artificial comparison and the published 2-DE gels, a total of seven significantly and consistently upregulated or downregulated protein spots (Student's $t$-test; $\mathrm{P}<0.05$ ) with fold-changes $>2$ in volume intensity were selected for MS (Fig. 4B).

Overall, six downregulated protein spots and one upregulated protein spot were successfully identified by the MALDI-TOF-MS spectra. The results of the MALDI-TOF MS/MS analysis and NCBInr database search for the proteins are listed in Table I, including the experimental molecular weight, PI, protein score of each protein spot, NCBI accession number and the coverage of peptides. The proteins were classified into the following major functional groups based on their functions: Oxidative stress-associated proteins, energy metabolism-associated enzymes, apoptosis induction-associated proteins, and cytoskeletal proteins (Table I).

Verification of 2-DE and MS analysis. The protein expression levels of stathmin, DHFR and TrxR were confirmed using western blot analysis (Fig. 5A and B) and the mRNA expression levels were assessed using RT-qPCR analysis (Fig. 5C and D). The changes in the protein and mRNA expression levels were comparable to the changes in protein expression levels found using 2-DE.

\section{Discussion}

Oridonin has exhibited antitumor properties in various cancer cell lines via the regulation of cell cycle, apoptosis and autophagy $(4,18)$. Investigations on the antitumor mechanism of oridonin have been limited to date. In the present study, it was found that oridonin inhibited the growth of LP-1 multiple myeloma cells in a time- and dose-dependent manner; an $\mathrm{IC}_{50}$ value of $25.1 \mu \mathrm{mol} / \mathrm{l}$ for $24 \mathrm{~h}$ was determined using an MTT assay. Flow cytometry and transmission electron microscopy analyses confirmed that oridonin inhibited the growth of the LP-1 cells by inducing apoptosis. To further investigate the molecular mechanisms underlying the anticancer effects of oridonin, proteomic analysis was performed to identify the differentially expressed proteins in the oridonin-treated LP-1 cells. In total, seven proteins were successfully identified. Among these were proteins associated with cell proliferation and apoptosis, and proteins involved in tumorigenesis and progression, including stathmin and DHFR. A number of the differentially expressed proteins were found to be involved in 
A

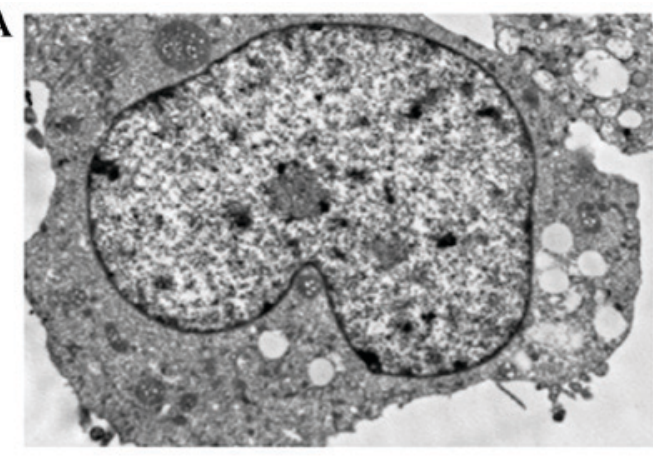

C

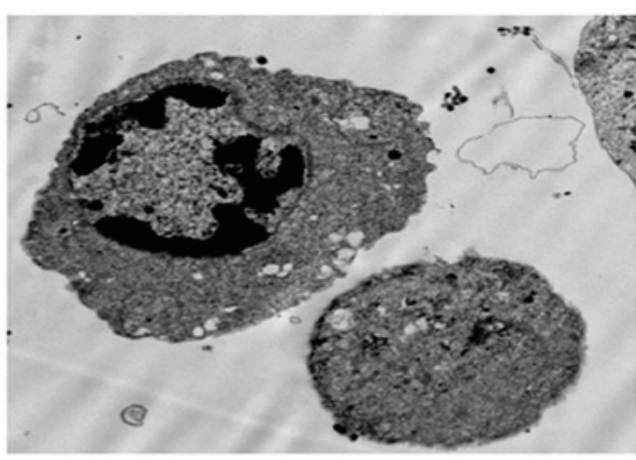

E

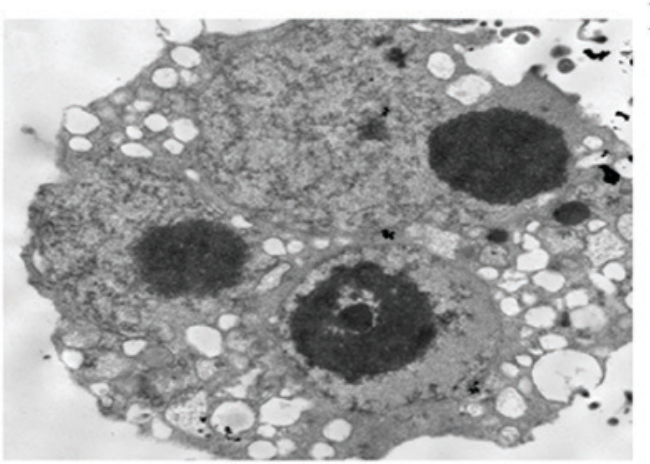



D

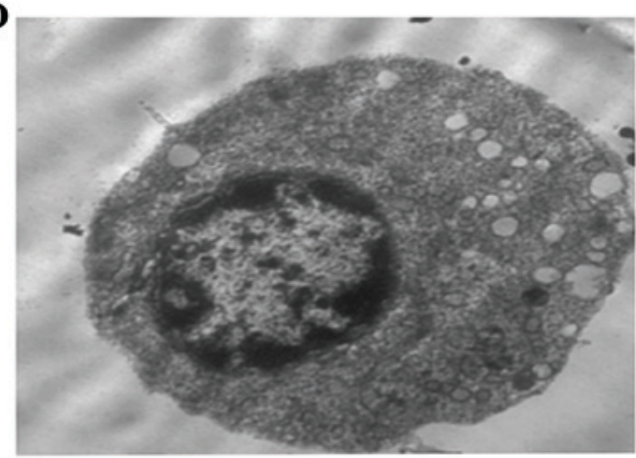

F

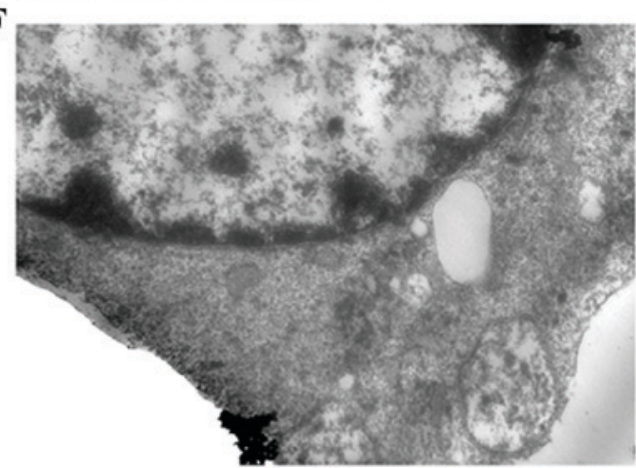

Figure 3. Ultrastructural alterations in LP-1 cells following exposure to $25 \mu \mathrm{M}$ oridonin for $24 \mathrm{~h}$. (A) Control LP-1 cells (magnification, $\mathrm{x} 4,000)$. (B) Control LP-1 cells (magnification, $x 8,000$ ). (C and D) Oridonin treatment for 24 h revealed chromatin condensation and cytoplasmic vacuolization (magnification, $\mathrm{x} 4,000)$. (E) Oridonin-treated cells exhibited cytoplasmic vacuolization and apoptotic bodies (magnification, x8,000). (F) At high magnification, mitochondrial swelling was observed (magnification, x20,000).

energy metabolism, including TrxR and pyruvate dehydrogenase $\mathrm{E} 1 \beta$ (PDHB). Heat shock protein 70 is considered to be an oxidative stress-inducible protein involved in oridonin-induced apoptosis (19).

Stathmin is a microtubule destabilizing protein, which is involved in the assembly of microtubules and spindles by binding to the tubulin protein (20). It is important in cell proliferation, differentiation, regeneration and migration, and has regulatory effects on signal transduction. In addition, stathmin has been reported to be overexpressed in a variety of human malignancies (21-23) and has been shown to induce tumor cell migration and invasion by regulating microtubule depolymerization. The post-translational modification of stathmin affects the interaction with the p53 protein, and is involved in the initiation and progression of malignant tumors (24). In the present study, it was demonstrated that the downregulation of stathmin was correlated with an inhibitory effect on the growth of the LP-1 cells following oridonin treatment. These results suggested that oridonin may inhibit proliferation of the LP-1 cells partially by downregulating stathmin. Stathmin may also have pro-apoptotic functions. As stathmin has been used, either alone or in combination with chemotherapeutics, for tumor therapy $(25,26)$, stathmin may be a potential target for anticancer drugs.

DHFR is a member of the reductase enzyme family, which is important in the carbon transfer process. DHFR catalyzes the NADPH-dependent reduction of dihydrofolate (DHF) to tetrahydrofolate (THF), which is necessary for several one-carbon transfer reactions in purine and pyrimidine synthesis (27). The reduction of DHFR enzymatic activity reduces the THF pool inside the cell, which affects the level of folate coenzymes, and thus reduces purine and pyrimidine synthesis (28). Due to the crucial role of DHFR in the conversion of DHF to THF, the inhibition of DHFR inhibits the key enzymes involved in folate metabolism; this inhibition can result in the disruption of purine and thymidylate biosynthesis, thereby inhibiting DNA replication and inducing tumor cell apoptosis. In the present study, the downregulation of DHFR may have contributed to the apoptotic and cell cycle-arresting effects of oridonin. The inhibition of DHFR is essential to 




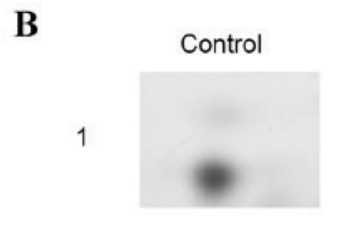

2

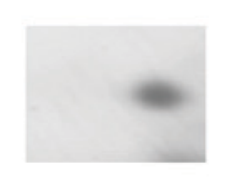

3

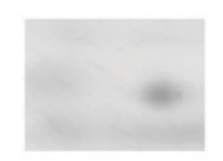

4

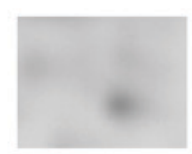

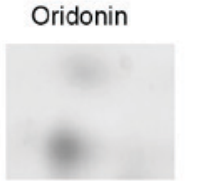
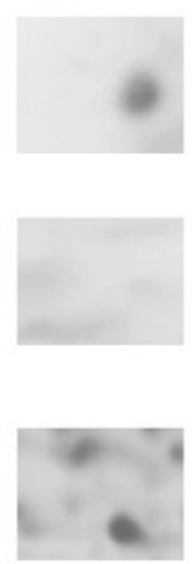
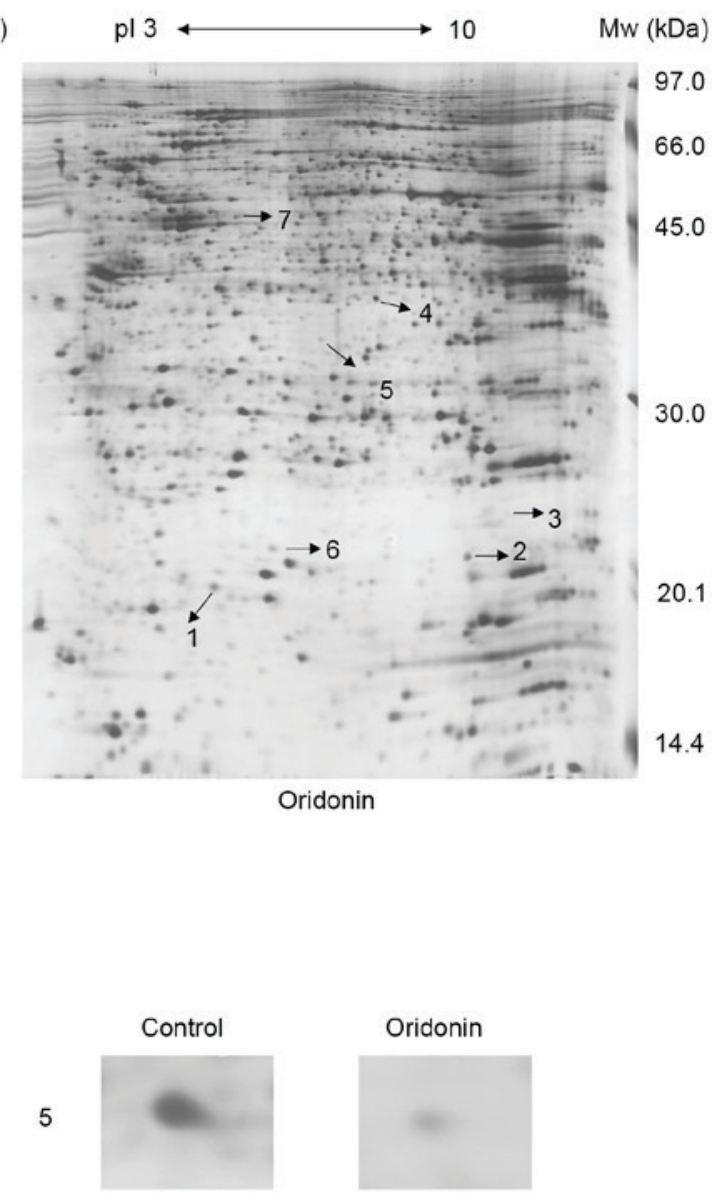

6


7
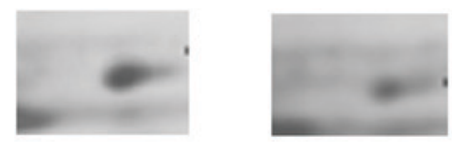

Figure 4. Representative two-dimensional electrophoresis gels stained with silver nitrate. (A) Gels were silver-stained. Cells were treated with dimethyl sulfoxide (control) or $25 \mu \mathrm{M}$ oridonin for $24 \mathrm{~h}$. (B) Seven protein spots with marked changes were identified and indicated in images of the spots. pI, isoelectric point.

the action of antifolate medications used to treat cancer and certain inflammatory diseases $(29,30)$. Therefore, oridonin may be offer potential as an antifolate drug in myeloma therapy.

Trx R is a homodimeric selenoprotein, which catalyzes the NADPH-dependent reduction of thioredoxin. Thioredoxin is a cofactor in protein disulfide reduction and DNA synthesis; independently, thioredoxin inhibits apoptosis, stimulates cell proliferation and increases transcription factor activity (31). Trx R is a potential molecular target of anticancer agents as it is overexpressed in several types of tumor cells, exhibits a prosurvival effect, and enhances tumor proliferation and resistance to therapeutic treatments (32). It has been shown that decreasing the expression of Trx $\mathrm{R}$ using a small interfering
RNA construct reverses the tumor morphology and the tumorigenic properties of lung cancer cells (33). In addition, targeting TrxR is a basis for cancer therapy by arsenic trioxide and cyclophosphamide $(34,35)$. These findings, together with the downregulation of TrxR observed the LP-1 cells treated with oridonin, indicate that the downregulation of Trx R may be one mechanism by which oridonin mediates its antitumor effects. Oridonin may induce the apoptosis of LP-1 cells via a reduction of the prosurvival effect and cell proliferation, contributing to antiproliferation and apoptosis of the LP-1 cells.

The PDH complex (PDC) is a mitochondrial multi-enzyme complex, which catalyzes the overall conversion of pyruvate to acetyl-CoA. The E1 component of PDC is a heterotetramer 
Table I. Matrix-assisted laser desorption/ionization time of flight mass spectrometry identification results of differentially expressed protein spots in oridonin-treated LP-1 cells.

\begin{tabular}{|c|c|c|c|c|c|c|c|c|}
\hline Spot & NCBInr ID & $\mathrm{Mr}(\mathrm{Da})$ & $\mathrm{pI}$ & Protein & Expression & $\begin{array}{c}\text { Sequence } \\
\text { coverage (\%) }\end{array}$ & Score & Function \\
\hline 1 & gil197692597 & 17,320 & 5.76 & Stathmin & Decrease & 46 & 102 & Proliferation inhibition \\
\hline 2 & gil170696334 & 18,438 & 6.43 & DHFR & Decrease & 46 & 93 & $\begin{array}{l}\text { Oxidation reduction, energy } \\
\text { metabolism }\end{array}$ \\
\hline 3 & gil37496526 & 18,491 & 8.22 & Cofilin 1 & Decrease & 51 & 101 & Cytoskeleton \\
\hline 4 & gil304373302 & 35,707 & 6.20 & PDHB & Increase & 24 & 117 & Oxidation reduction \\
\hline 5 & gil304373227 & 33,180 & 5.85 & TrxR & Decrease & 36 & 127 & Oxidation reduction \\
\hline 6 & gil62901936 & 20,210 & 6.03 & LAP p18 & Decrease & 39 & 109 & Proliferation inhibition \\
\hline 7 & gil52783267 & 70,854 & 5.37 & HSP 70 & Decrease & 36 & 107 & Stress resistance \\
\hline
\end{tabular}

pI, isoelectric point; DHFR, dihydrofolate reductase; PDHB, pyruvate dehydrogenase E1 $\beta$; TrxR, thioredoxin reductase; LAP p18, leukemia-associated phosphoprotein p18; HSP 70, heat shock protein 70.
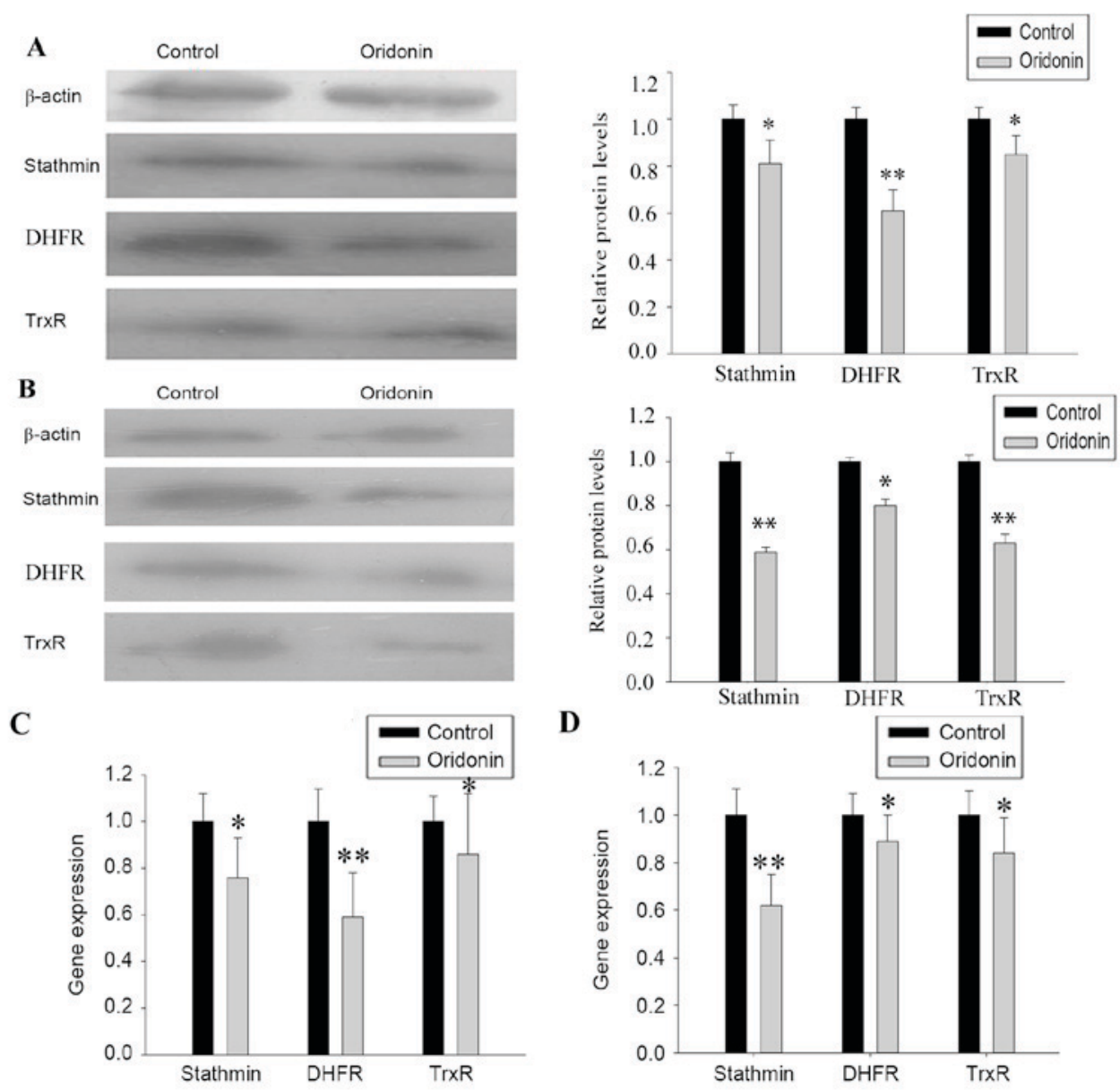

Figure 5. Alterations in the protein and mRNA expression levels of stathmin, DHFR and TrxR in LP-1 cells and 8226 cells treated with $25 \mu \mathrm{M}$ oridonin for $24 \mathrm{~h}$. Western blot analysis of the protein levels of stathmin, DHFR and TrxR in (A) LP-1 cells and (B) 8226 cells. Reverse transcription-quantitative polymerase chain reaction analysis of the mRNA expression levels of stathmin, DHFR and TrxR in (C) LP-1 cells and (D) 8226 cells. ${ }^{*} \mathrm{P}<0.05$ and ${ }^{* *} \mathrm{P}<0.01$, vs. control. DHFR, dihydrofolate reductase; TrxR, thioredoxin reductase.

of two $\alpha$ and two $\beta$ subunits (PDHB), which are key in the decarboxylation of pyruvate. The majority of types of cancer rely disproportionately on glycolysis for energy, even in the presence of an adequate supply of oxygen, which is a condition known as the Warburg effect (36). Reversal of the Warburg effect has been shown to cause the selective apoptosis of tumor cells by stimulating mitochondrial respiratory chain activity (37). The present study hypothesized that oridonin 
may act as an antitumor agent in a similar manner by upregulating the expression of PDHB and the activity of PDC, which subsequently leads to the upregulation of glucose oxidation and downregulation of glycolysis in the cytosol. Additionally, the increased carbon flux through the tricarboxylic cycle and respiratory chain activity catalyze the production of reactive oxygen species, which consequently induces depolarization of the mitochondrial membrane potential, resulting in the release of cytochrome $c$ and the stimulation of caspase-mediated cell death (38).

In conclusion, the present study is, to the best of our knowledge, the first to systematically identify and characterize the global proteome of apoptosis induced by oridonin in LP-1 cells. The proteomic profiling technique provided an effective approach to elucidate the antitumor mechanism of oridonin.

The present study demonstrated that treatment of the LP-1 cells with oridonin induced significant changes in the expression of multiple proteins. The identification of functionally modulated proteins involved in the oridonin-treated LP-1 cells improves current understanding of the antitumor effect of oridonin at the molecular level. The expression and functional regulation of target proteins, stathmin, DHFR and PDHB, may represent novel effective therapeutic strategies for multiple myeloma. These observations improves understanding of the molecular mechanism underlying the oridonin-induced apoptosis of LP-1 cells in vitro and assists in the identification of possible targets for cancer intervention.

\section{Acknowledgements}

This study was supported by the Natural Science Foundation for Young Scholars of China (grant no. 81000218). The authors would like to thank the Proteome Laboratory of the Institute of Basic Medical Sciences, National Center of Biomedical Analysis (Beijing, China), for the proteomic analyses.

\section{References}

1. Sirohi B and Powles R: Multiple myeloma. Lancet 363: 875-887, 2004.

2. Mahindra A, Laubach J, Raje N, Munshi N, Richardson PG and Anderson K: Latest advances and current challenges in the treatment of multiple myeloma. Nat Rev Clin Oncol 9: 135-143, 2012

3. Cheng Y, Qiu F, Ye YC, Tashiro S, Onodera S and Ikejima T: Oridonin induces $\mathrm{G} 2 / \mathrm{M}$ arrest and apoptosis via activating ERK-p53 apoptotic pathway and inhibiting PTK-Ras-Raf-JNK survival pathway in murine fibrosarcoma L929 cells. Arch Biochem Biophys 490: 70-75, 2009.

4. Yang J, Jiang H, Wang C, Yang B, Zhao L, Hu D, Qiu G, Dong X and Xiao B: Oridonin triggers apoptosis in colorectal carcinoma cells and suppression of microRNA-32 expression augments oridonin-mediated apoptotic effects. Biomed Pharmacother 72 125-134, 2015.

5. Kang N, Zhang JH, Qiu F, Tashiro S, Onodera S and Ikejima T: Inhibition of EGFR signaling augments oridonin-induced apoptosis in human laryngeal cancer cells via enhancing oxidative stress coincident with activation of both the intrinsic and extrinsic apoptotic pathways. Cancer Lett 294: 147-158, 2010.

6. Lou H, Zhang X, Gao L, Feng F, Wang J, Wei X, Yu Z, Zhang D and Zhang Q: In vitro and in vivo antitumor activity of oridonin nanosuspension. Int J Pharm 379: 181-186, 2009.

7. Liu YQ, Mu ZQ, You S, Tashiro S, Onodera S and Ikejima T: Fas/FasL Signaling allows extracelluar-signal regulated kinase to regulate cytochrome $\mathrm{c}$ release in oridonin-induced apoptotic u937 cells. Biol Pharm Bull 29: 1873-1879, 2006.
8. Ren KK, Wang HZ, Xie LP, Chen DW, Liu X, Sun J, Nie YC and Zhang RQ: The effects of oridonin on cell growth, cell cycle, cell migration and differentiation in melanoma cells. J Ethnopharmacol 103: 176-180, 2006.

9. Zhang Y, Wu Y, Tashiro S, Onodera S and Ikejima T: Involvement of PKC signal pathways in oridonin-induced autophagy in HeLa cells: A protective mechanism against apoptosis. Biochem Biophys Res Commun 378: 273-278, 2009.

10. Hsieh TC, Wijeratne EK, Liang JY, Gunatilaka AL and Wu JM: Differential control of growth, cell cycle progression and expression of NF-kappaB in human breast cancer cells MCF-7, MCF-10A, and MDA-MB-231 by ponicidin and oridonin, diterpenoids from the chinese herb Rabdosia rubescens. Biochem Biophys Res Commun 337: 224-231, 2005.

11. Hanash SM, Madoz-Gurpide J and Misek DE: Identification of novel targets for cancer therapy using expression proteomics. Leukemia 16: 478-485, 2002.

12. Ramagli L: Quantifying protein in 2-D PAGE solubilization buffers. In: 2-D Proteome Analysis Protocols. Link AJ (ed). Vol 112. Humana Press, Totowa, NJ, pp99-103, 1999.

13. Görg A, Postel W and Günther S: The current state of two-dimensional electrophoresis with immobilized $\mathrm{pH}$ gradients. Electrophoresis 9: 531-546, 1988.

14. B Tom ST: 2-D electrophoresis using immobilized $\mathrm{pH}$ gradients, pricinples and methods. Amersham Pharmacia Biotech, 1998.

15. Pasquali C, Fialka I and Huber LA: Preparative two-dimensional gel electrophoresis of membrane proteins. Electrophosis 18: 2573-2781, 1997.

16. Iversen LF, Kastrup JS, Bjørn SE, Wiberg FC, Larsen IK, Flodgaard HJ and Rasmussen PB: Structure and function of the N-linked glycans of HBP/CAP37/azurocidin: Crystal structure determination and biological characterization of nonglycosylated HBP. Protein Sci 8: 2019-2026, 1999.

17. Livak KJ and Schmittgen TD: Analysis of relative gene expression data using real-time quantitative PCR and the 2(-Delta Delta C(T)) Method. Methods 25: 402-408, 2001.

18. Zhu Y, Xie L, Chen G, Chen G, Wang H and Zhang R: Effects of oridonin on proliferation of HT29 human colon carcinoma cell lines both in vitro and in vivo in mice. Pharmazie 62: 439-444, 2007.

19. Dal Piaz F, Cotugno R, Lepore L, Vassallo A, Malafronte N, Lauro G, Bifulco G, Belisario MA and De Tommasi N: Chemical proteomics reveals HSP70 1A as a target for the anticancer diterpene oridonin in Jurkat cells. J Proteomics 82: 14-26, 2013.

20. Charbaut E, Curmi PA, Ozon S, Lachkar S, Redeker V and Sobel A: Stathmin family proteins display specific molecular and tubulin binding properties. J Biol Chem 276: 16146-16154, 2001.

21. Alli E, Yang JM and Hait WN: Silencing of stathmin induces tumor-suppressor function in breast cancer cell lines harboring mutant p53. Oncogene 26: 1003-1012, 2007.

22. Mistry SJ, Bank A and Atweh GF: Targeting stathmin in prostate cancer. Mol Cancer Ther 4: 1821-1829, 2005.

23. Mistry SJ and Atweh GF: Therapeutic interactions between stathmin inhibition and chemotherapeutic agents in prostate cancer. Mol Cancer Ther 5: 3248-3257, 2006.

24. Yuan RH, Jeng YM, Chen HL, Lai PL, Pan HW, Hsieh FJ, Lin CY, Lee PH and Hsu HC: Stathmin overexpression cooperates with p53 mutation and osteopontin overexpression, and is associated with tumour progression, early recurrence, and poor prognosis in hepatocellular carcinoma. J Pathol 209: 549-558, 2006.

25. Zhang HZ, Wang Y, Gao P, Lin F, Liu L, Yu B, Ren JH, Zhao H and Wang R: Silencing stathmin gene expression by survivin promoter-driven siRNA vector to reverse malignant phenotype of tumor cells. Cancer Biol Ther 5: 1457-1461, 2006.

26. Iancu C, Mistry SJ, Arkin S and Atweh GF: Taxol and anti-stathmin therapy: A synergistic combination that targets the mitotic spindle. Cancer Res 60: 3537-3541, 2000.

27. Jensen DE, Black AR, Swick AG and Azizkhan JC: Distinct roles for $\mathrm{Sp} 1$ and $\mathrm{E} 2 \mathrm{~F}$ sites in the growth/cell cycle regulation of the DHFR promoter. J Cell Biochem 67: 24-31, 1997.

28. Chen MJ, Shimada T, Moulton AD, Cline A, Humphries RK, Maizel J and Nienhuis AW: The functional human dihydrofolate reductase gene. J Biol Chem 259: 3933-3943, 1984.

29. Assaraf YG: Molecular basis of antifolate resistance. Cancer Metastasis Rev 26: 153-181, 2007.

30. Morales C, García MJ, Ribas M, Miró R, Muñoz M, Caldas C and Peinado MA: Dihydrofolate reductase amplification and sensitization to methotrexate of methotrexate-resistant colon cancer cells. Mol Cancer Ther 8: 424-432, 2009. 
31. Biaglow JE and Miller RA: The thioredoxin reductase/thioredoxin system: Novel redox targets for cancer therapy. Cancer Biol Ther 4: 6-13, 2005.

32. Nguyen P, Awwad RT, Smart DD, Spitz DR and Gius D: Thioredoxin reductase as a novel molecular target for cancer therapy. Cancer Lett 236: 164-174, 2006.

33. Yoo MH, Xu XM, Carlson BA, Gladyshev VN and Hatfield DL: Thioredoxin reductase 1 deficiency reverses tumor phenotype and tumorigenicity of lung carcinoma cells. J Biol Chem 281: 13005-13008, 2006.

34. Lu J, Chew EH and Holmgren A: Targeting thioredoxin reductase is a basis for cancer therapy by arsenic trioxide. Proc Natl Acad Sci USA 104: 12288-12293, 2007

35. Wang $\mathrm{X}$, Zhang $\mathrm{J}$ and $\mathrm{Xu} \mathrm{T}$ : Cyclophosphamide as a potent inhibitor of tumor thioredoxin reductase in vivo. Toxicol Appl Pharmacol 218: 88-95, 2007.
36. Glushakova LG, Lisankie MJ, Eruslanov EB, Ojano-Dirain C, Zolotukhin I, Liu C, Srivastava A and Stacpoole PW: AAV3-mediated transfer and expression of the pyruvate dehydrogenase E1 alpha subunit gene causes metabolic remodeling and apoptosis of human liver cancer cells. Mol Genet Metab 98: 289-299, 2009.

37. Lu J, Tan M and Cai Q: The Warburg effect in tumor progression: Mitochondrial oxidative metabolism as an anti-metastasis mechanism. Cancer Lett 356: 156-164, 2015.

38. Michelakis ED, Webster L and Mackey JR: Dichloroacetate (DCA) as a potential metabolic-targeting therapy for cancer. Br J Cancer 99: 989-994, 2008. 